\title{
Livestock out of balance. From asset to liability in the course of the livestock revolution - ERRATUM
}

\author{
Animal Genetic Resources, volume 51, page 156.
}

The text of the recent publication announcement for Livestock out of balance. From asset to liability in the course of the livestock revolution was inadvertently replaced by that of another publication. We apologize for this oversight and reproduce the correct announcement here.

\section{Livestock out of balance. From asset to liability in the course of the livestock revolution}

\section{E. Mathias}

League for Pastoral Peoples and Endogenous Development Published in 2012, pp. 30

Available at http://www.pastoralpeoples.org/wp-content/ uploads/2012/04/Livestock-from-asset-to-liability-11.pdf

This discussion paper prepared for the League for Pastoral Peoples and Endogenous Development seeks to evaluate the effect that the so-called livestock revolution - the rapid expansion of industrialized livestock production into developing countries - is having on small-scale livestock producers. A review of the development of the livestock sector over the last decade concludes that some, but not all, of the assumptions underpinning the "livestock revolution" analysis put forward by the International Food Policy Research Institute in 1999 have been borne out. It is argued, for example, that the revolution - rather than having become a global phenomenon - is largely restricted to a few fast-growing economies, with much of the rest of the developing world having experienced, at best, only marginal growth in livestock production. Also highlighted are the higher-than-predicted prices of cereals and other inputs and the emergence of new animal health problems such as highly pathogenic avian influenza. On the policy side, it is argued that the phenomenon of government support for high external input livestock production, via research, advisory services, credit, subsidies and legislation - previously restricted to the developed world and a small number of developing countries - is becoming more widespread, while at the same time nonindustrialized livestock production is being neglected. The next section of the paper presents a short discussion of contract farming and similar arrangements that can provide entry points for the participation of small-scale producers in the livestock revolution. It is argued that while, particularly in their initial phases, such schemes may offer attractive benefits, such as inputs at low prices, there is a tendency for their terms to become harsher over time as intensification increases and the value chain becomes more specialized. This section is followed by a discussion of factors that lead farmers to invest in external

\section{Livestock out of balance From asset to liability in the course of the livestock revolution}

\section{Discussion paper}

Evelyn Mathias

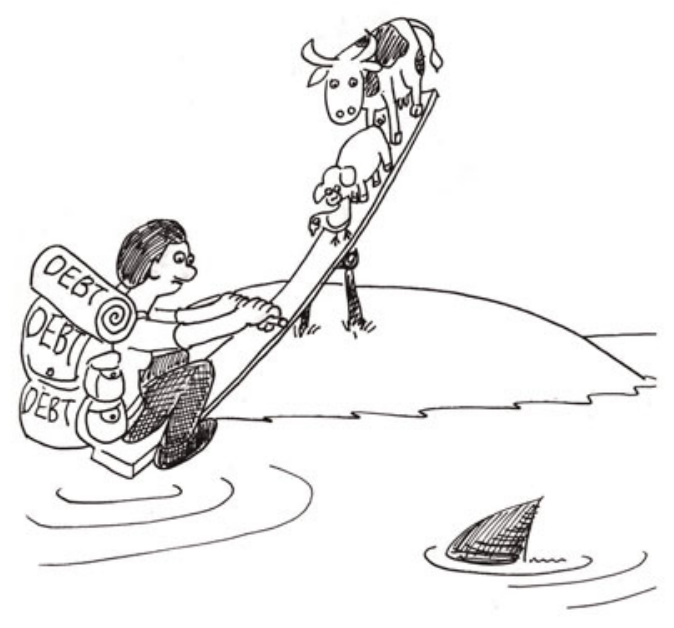

League for Pastoral Peoples and Endogenous Livestock Development

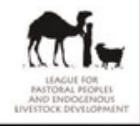

inputs and link up with commercial buyers. A range of factors are highlighted, including advice from extensionists and other sources, a lack of alternative opportunities, and fear of losing out in competition with those who do invest. The next step in the analysis is a review the various pressures that farmers face once they have embarked on a more commercially oriented approach, including competition from larger producers who benefit from economies of scale, reduced bargaining power because of consolidation in the processing and retailing sector, the need to comply with an ever-expanding number of laws and regulations affecting the production and marketing of animal products, and a range of unfavourable conditions that may be 
included in contractual arrangements. Moving on to the outcomes of the process, the paper discusses the rise of indebtedness among farmers and the tendency for specialization to reduce farmers' flexibility in the face of changing market demands and to leave them vulnerable to shocks such as disease outbreaks or increases in feed prices. At this point, the impact on animal genetic resources - growing dominance of a few higher-yielding breeds at the expense of a diverse range of locally adapted, often multipurpose breeds - is noted. The next section of the paper addresses consequences for the environment and for public health. It is argued that the financial pressures faced by farmers increase the risk that they will cut corners in terms of the proper disposal of waste products or will adopt dangerous production practices such as the misuse of antibiotics and other growth stimulants. The paper's concluding section calls on policymakers, scientists and development professionals to recognize that the negative consequences of the livestock revolution are not simply the unfolding of inevitable economic trends, but are also influenced by policies. What is needed - it is argued - are policies that create a level playing field for small producers and help them avoid falling into the trap of debt. 